\title{
Tüberküloz hastaları nerede tanı alıyor ve tedavisi başlanıyor?
}

\author{
Tarkan ÖZDEMIR ${ }^{1}$ \\ ibrahim Halil AKKUŞ ${ }^{2}$ \\ Mustafa H. TÜRKKANI ${ }^{3}$ \\ Leyla YILMAZ AYDIN ${ }^{4}$
}

${ }^{1}$ Elazığ ili Kamu Hastaneleri Birliği Genel Sekreterliği, Elazığ, Türkiye

${ }^{1}$ Elazig General Secretary of the Union Public Hospital, Elazig, Turkey

2 Elazığ Halk Sağlığı Müdürlüğü, Elazığ, Türkiye

2 Elazig Directorship of Public Health, Elazig, Turkey

${ }^{3}$ Ankara Fizik Tedavi ve Rehabilitasyon Eğitim ve Araştırma Hastanesi, Gögüus Hastalıkları, Ankara, Türkiye

${ }^{3}$ Ankara Physical Therapy and Rehabilitation Training and Research Hospital, Chest Diseases, Ankara, Turkey

${ }^{4}$ Düzce Üniversitesi Tıp Fakültesi, Göğüs Hastalıkları Anabilim Dalı, Düzce, Türkiye

${ }^{4}$ Department of Chest Diseases, Faculty of Medicine, Duzce University, Duzce, Turkey

\section{ÖZET}

Tüberküloz hastaları nerede tanı alıyor ve tedavisi başlanıyor?

Giriş: Tüberküloz hasta yönetiminde verem savaş dispanserleri (VSD) önemli roller üstlenmişlerdir. Tüberküloz hastalarına, VSD yanı sıra diğer sağlık kurumlarında da tanı konulmakta ve tedavi başlanmaktadır. Diğer kurumlar, VSD'lerin özellikle tedavi aşamasında ve hastaların takibinde bu misyonun farkında olması gerekir. Tüberküloz hastalarının hangi sağlık kurumunda tanı konulduğu ve tedaviye başlanıldığını ve VSD'lerin farkındalığının yeterli olup olmadığını inceledik.

Hastalar ve Metod: Elazığ VSD'de tüberküloz hastalarının dosyaları retrospektif olarak incelenmiş, elde edilen bilgiler Microsoft Excel'de analiz edilmiştir.

Bulgular: Elazı ̆ VSD'de 2005-2011 yıllarında takip edilen 854 tüberküloz hastasının dosya bilgilerine ulaşılmıştır. Hastaların \%36.3 ( $n=310$ )'üne üniversite hastanelerinde, \%18.5 ( $n=158$ )'ine VSD'de, \%17.3 ( $n=148)^{\prime}$ üne devlet hastanelerinde tanı konulmuştur. Tanı koyulan bu hastaların \%81.9 ( $n=699)^{\prime}$ 'una VSD'de, \%7.7 ( $\left.n=46\right)^{\prime}$ sine üniversite hastanelerinde, \%4.3 (n= 37)'üne göğüs hastalıkları hastanelerinde tüberküloz tedavisi başlanmıştır.

Sonuç: Hastanelerde tanı konan hastaların tedavilerine başlanmak üzere yönlendirildiği ve ilk ilaçları buradan verildiği için VSD’lerde tedavi başlama oranlarının yüksek olduğu tespit edilmiştir. Tüberküloz kontrol programında dispanserler hasta yönetiminde önemli işlevsel fonksiyonlar yürütmektedir ve diğer kurumlar bu durumun farkındadırlar.

Anahtar kelimeler: Tüberküloz, tanı, tedavi

\section{SUMMARY}

Where the tuberculosis patients are diagnosed and started to treatment?

Introduction: Tuberculosis dispensaries have played important roles in management of patients with tuberculosis. Tuberculosis

\section{Yazışma Adresi (Address for Correspondence)}

Dr. Tarkan ÖZDEMiR

Elazığ İli Kamu Hastaneleri Birliği Genel Sekreterliği,

ELAZIĞ - TURKEY

e-mail: tabiptarkan@hotmail.com 
patients diagnosed and treatments are started at dispensaries as well as other health care institutions. Other institutions must be aware of the mission of dispensaries especially at the treatment and follow-up of patients. We aimed to investigate in which health care institutions tuberculosis patients diagnosed and treatment started and whether the awareness about dispanseries is sufficient.

Patients and Methods: Records of tuberculosis patients in Elazıg dispansery examined retrospectively. The data obtained were analyzed by Microsoft Excel.

Results: Records of 854 patients with tuberculosis has been reached those followed in Elazig dispensary between the years 2005-2011. Percentages of the patients diagnosed in university hospital, dispensary and state hospitals were $36.3 \%, 18.5 \%$ and $17.3 \%$; respectively. Treatments of patients were started in dispensary (81.9\%), university hospital (7.7\%), and chest disease hospital (4.3\%).

Conclusion: Treatment starting rate of dispensary was high because patients diagnosed by other health institutions directed to dispensary for taking the first drugs and beginning of the treatment. In tuberculosis control program; dispensaries carry out important operational functions in management of tuberculosis patients and other health institutions are aware of this situation.

Key words: Tuberculosis, diagnosis, treatment

\section{Giriş}

Türkiye'de tüberküloz kontrolü, tarihsel birikimi olan, bütünlüklü bir yaklaşıma sahip ve hep öncelikli bir sağlık sorunu olarak ele alınmıştır. Bu programın, BCG aşısı ve toplum taraması öncelikli yaklaşımdan tanı ve tedavi ağırlıklı bir yaklaşıma dönmesi son 30 yılda gerçekleşmiş̧ir (1).

Dünya Sağlık Örgütü'nün önerdiği Doğrudan Gözetimli Tedavi Strateji'sinin temel unsurları ise son on yılda önemli çabaların sonucunda uygulanmıştır. Bugün Stop TB Stratejisi'nin daha yetkin bir konuma ulaşması için gayret gösterilmektedir (2).

Verem savaş dispanserleri (VSD) tüberküloz kontrol programının önemli bir birimidir. Dispanserler; tanı, tedavi, takip, hasta bildirimi, kayıt, istatistik, bağışıklama, tarama, ilaç ikmali, eğitim, propaganda faaliyetleri, koordinasyon ve danışmanlık hizmetlerini yürüten sağlık kurumlarıdır. VSD'ler, tüberküloz hasta ve ailesini bir bütün olarak değerlendirir, hasta merkezli yaklaşım gösterir. VSD, bölgesinde Stop TB Stratejisi'nin bir bütün olarak bütün unsurlarıyla uygulanmasını sağlar.

Bu çalışmada, tüberküloz hastalarına hangi să̆lık kurumunda tanı konulduğu ve tedaviye başlandığının tespit edilmesi amaçlanmıştır. il düzeyinde dispanser faaliyetlerini araştıran çalışmalarda bu konuda değerlendirmeler olmasına rağmen kapsamlı bir çalışma yoktu. Bu çalışma ile tüberküloz kontrol programı kapsamında VSD'lerin öneminin gösterilmesi hedeflenmiş̧tir.

\section{MATERYAL ve METOD}

Çalışmamızda, 2005-2011 yılları arasında Elazığ VSD'de takip edilen tüberküloz hastalarına tanı koyan ve tedavi başlayan sağlık kurumlarının bilgisi araştırılmıştır. Hastaların dosyaları retrospektif olarak incelenmesi ile elde edilen bilgiler yığma veri olarak toplanmış, Excel'de analiz edilmiş ve tablolar oluşturulmuştur.

\section{BULGULAR}

Elazığ VSD'de 2005-2011 yıllarında takip edilen 854 tüberküloz hastasının dosya bilgilerine ulaşılmıştır. Dosya bilgilerine ulaşılan 854 hastanın \%58.6 ( $\mathrm{n}=$ 501)'sı akciğer, \%41.4 ( $n=353)^{\prime}$ ü akciğer dışı tüberkülozludur (Tablo 1). Çalışmamızda akciğer + akciğer dışı tüberküloz hastaları akciğer tüberküloz grubunda yer almıştır.

Hastalarının \%36.3 ( $\mathrm{n}=310)$ 'üne üniversite hastanelerinde, \%18.5 ( $n=158)^{\prime}$ ine VSD'de, \%17.3 ( $\left.n=148\right)^{\prime}$ üne devlet hastanelerinde tanı konulmuştur (Tablo 2).

Tanı koyulan bu hastaların \%81.9 ( $\mathrm{n}=6999)$ 'una VSD'de, \%7.7 ( $n=46)^{\prime}$ 'sine üniversite hastanelerinde, \%4.3 ( $\mathrm{n}=37)^{\prime}$ üne göğüs hastalıkları hastanelerinde tüberküloz tedavisi başlanmıştır (Tablo 3).

Akciğer tüberküloz hastalarının tanılarının konulduğu sağlık kurumlarının yıllara göre dağılımı Tablo 4'te yer almaktadır.

Akciğer dışı tüberküloz hastalarının tanılarının konulduğu sağlık kurumlarının yıllara göre dağılımı Tablo 5 'de yer almaktadır.

Akciğer tüberküloz hastalarının tedavilerinin başlandığı sağlık kurumları yıllara göre dağılımı Tablo 6 'da yer almaktadır.

Akciğer dışı tüberküloz hastalarının tedavilerinin başlandığı sağlık kurumları yıllara göre dağııımı Tablo 7'de yer almaktadır. 
Tablo 1. Olguların tutulum yerine göre dağılımı, 2005-2011

\begin{tabular}{|cccc|}
\hline Yıllar & Akciğer* & Akciğer dışı & Toplam \\
\hline 2005 & 92 & 52 & 149 \\
2006 & 73 & 44 & 117 \\
2007 & 70 & 56 & 126 \\
2008 & 71 & 46 & 117 \\
2009 & 66 & 49 & 115 \\
2010 & 73 & 64 & 137 \\
2011 & 56 & 42 & 98 \\
Toplam & 501 & 353 & 854 \\
\hline * Akciğer + Akciğer dışı tüberküloz hastaları akciğer tüberkülozda yer almıştır. & & \\
\hline
\end{tabular}

Tablo 2. Tüberküloz olgularının tanılarının konulduğu sağıık kurumları

\begin{tabular}{|c|c|c|c|}
\hline Tanı koyan kurum & $\begin{array}{l}\text { Akciğer } \\
\% \text { (n) }\end{array}$ & $\begin{array}{c}\text { Akciğer dışı } \\
\% \text { (n) }\end{array}$ & $\begin{array}{l}\text { Toplam } \\
\%(n)\end{array}$ \\
\hline Referans hastaneler* & $3.5(18)$ & $1.4(3)$ & $2.5(21)$ \\
\hline Üniversite hastaneleri & $22.8(114)$ & $55.5(196)$ & $36.3(310)$ \\
\hline Verem savaşı dispanseri & $31.3(157)$ & $0.3(1)$ & $18.5(158)$ \\
\hline Göğüs hastalıkları hastaneleri & $7.4(37)$ & $2.0(7)$ & $5.2(44)$ \\
\hline Devlet hastaneleri & $16(80)$ & $18.7(68)$ & $17.3(148)$ \\
\hline Eğitim ve araştırma hastaneleri & $6.8(34)$ & $6.8(24)$ & $6.8(58)$ \\
\hline Özel hastaneler & $10.6(53)$ & $13.3(47)$ & $11.7(100)$ \\
\hline Askeri hastaneler & $1.6(8)$ & $1.7(6)$ & $2(14)$ \\
\hline Diğer & - & $0.3(1)$ & $0.1(1)$ \\
\hline Toplam & $100(501)$ & $100(353)$ & $100(854)$ \\
\hline
\end{tabular}

Tablo 3. Tüberküloz olgularının tedavilerinin başlandığı sağlık kurumları

\begin{tabular}{lccc|} 
Tedaviyi başlayan kurum & $\begin{array}{c}\text { Akciğer } \\
\text { \% (n) }\end{array}$ & $\begin{array}{c}\text { Akciğer dışı } \\
\text { \% (n) }\end{array}$ & $\begin{array}{c}\text { Toplam } \\
\text { \% (n) }\end{array}$ \\
\hline Referans hastaneler & $2(9)$ & - & $1.1(9)$ \\
Üniversite hastaneleri & $4.6(23)$ & $12.2(43)$ & $7.7(66)$ \\
Verem savaşı dispanseri & $83.6(419)$ & $79.3(280)$ & $81.9(699)$ \\
Göğüs hastalıkları hastaneleri & $6.6(33)$ & $1.1(4)$ & $4.3(37)$ \\
Devlet hastaneleri & $1.2(6)$ & $5.7(20)$ & $3.0(26)$ \\
Eğitim ve araştırma hastaneleri & $0.5(3)$ & - & $0.4(3)$ \\
Özel hastaneler & $0.2(1)$ & $1.1(4)$ & $0.6(5)$ \\
Asker hastaneleri & $0.7(4)$ & $0.6(2)$ & $0.7(6)$ \\
Diğer & $0.6(3)$ & - & $0.3(3)$ \\
Toplam & $100(501)$ & $100(353)$ & $100(854)$ \\
\hline
\end{tabular}

\section{TARTIŞMA}

Dispanserler, Stop TB Stratejisi ve Uluslararası Tüberküloz Bakım Standartları esas alarak, her bireyin ya da hastanın en iyi korunma önlemlerinden, tanı ve tedaviden yararlanmasını sağlayacak ana faaliyetleri kendisi ya da diğer kurumlarında katılımı ile yapar.

Tüberküloz kontrol programında uç birim VSD'dir. VSD’nin görevi; tüberküloz hastasında; erken ve bak 

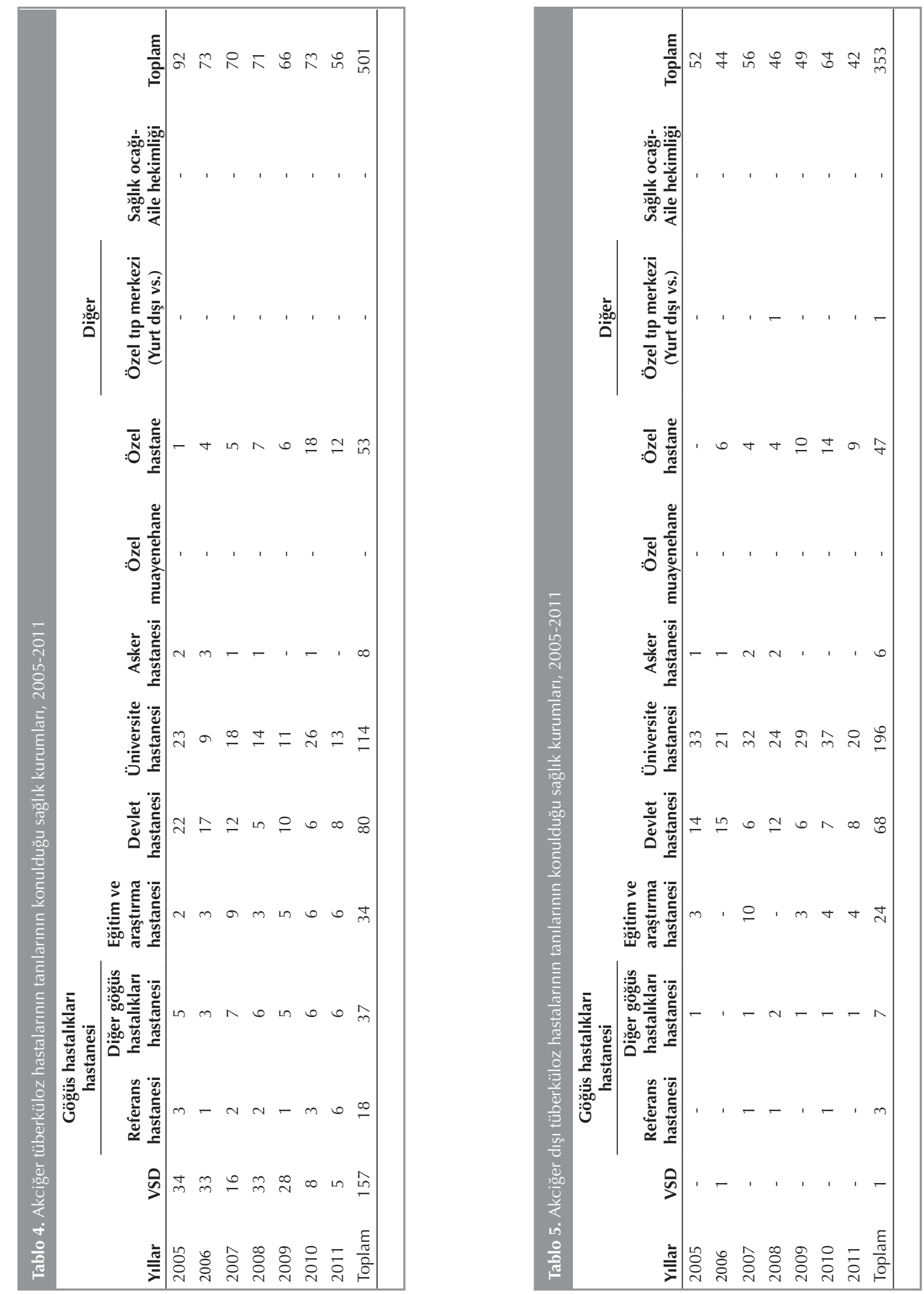

\footnotetext{
188 Tuberk Toraks 2015;63(3):185-191
} 
Özdemir T, Akkuş ï, Türkkanı MH, Yılmaz Aydın L.
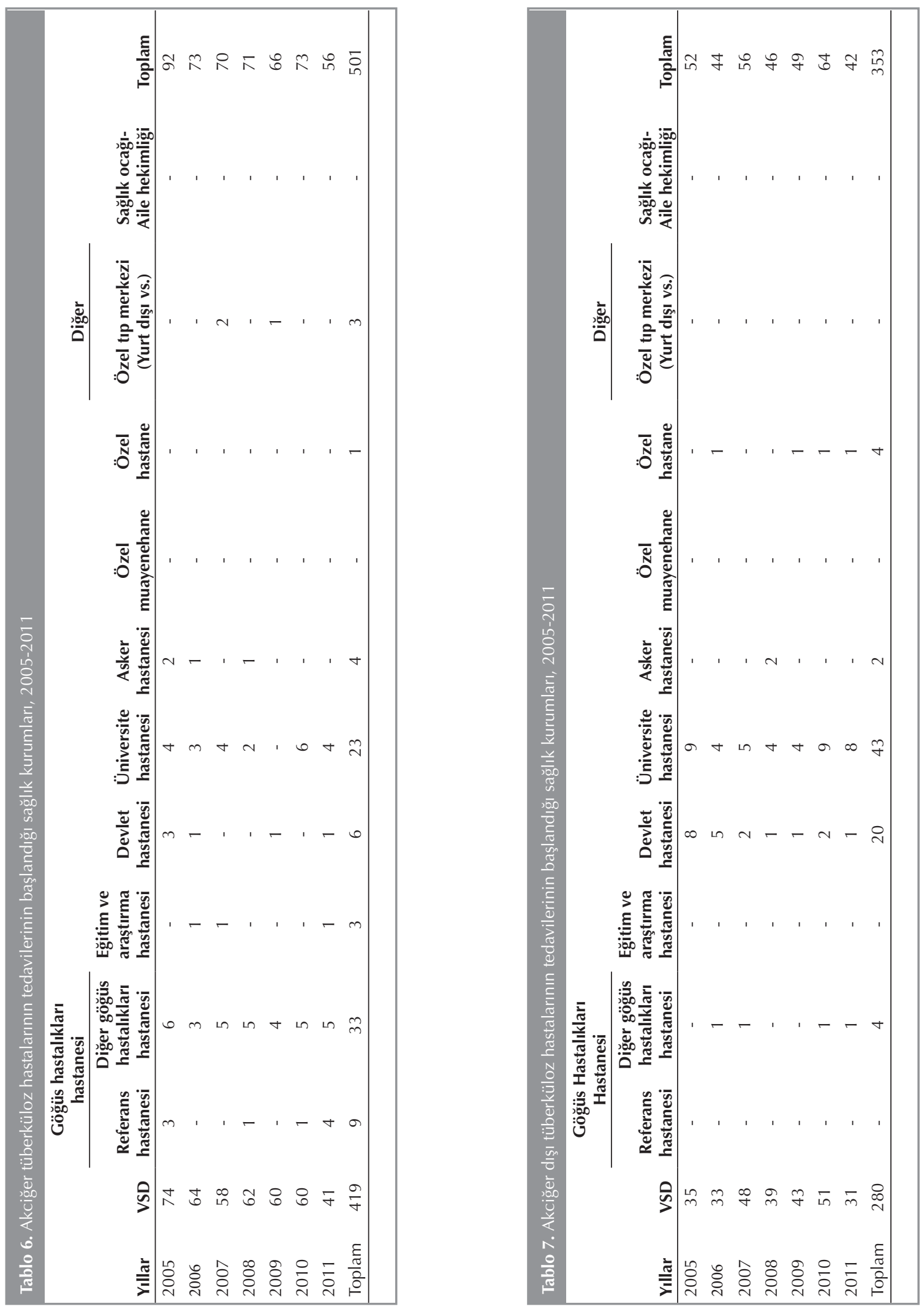

Tuberk Toraks 2015;63(3):185-191 $189 \square$ 
teriyolojinin esaslı tanı koyma, hastanın bildirimi, aile bireyleri ve yakın temaslılarının taranması ve gerekiyorsa koruyucu tedavileri; tedavi başlangıcında ilaç duyarlılık testlerinin yapılması; hastaya standart/doğru tedavi rejiminin başlanması; tedavinin klinik ve radyolojik bulgular yanında bakteriyolojik takibi; tedavisi süresince bütün ilaç dozlarının gözetimli olarak içirilmesinin sağlanması; tedaviyi sürdüren kurumlar arasında hastanın naklinin sağlam bir şekilde yapılması ve tedavinin tamamlanmasıdır.

Ülke genelinde 2011 yılı sonu itibariyle her bölgeye eşit olarak dağılmış 194 VSD bulunmaktadır. Ayrıca 20 ilde 21 tüberküloz bölge laboratuvarı, 18 mobil tarama ekibi, dördü eğitim ve araştırma hastanesi olmak üzere 12 göğüs hastalıkları hastanesi ile tüberküloz kontrolü için uygun bir altyapı bulunmaktadır (2).

Ankara Atatürk, İstanbul Yedikule, İstanbul Süreyyapaşa ve İzmir Dr. Suat Seren Göğüs Hastalıkları ve Göğüs Cerrahisi Eğitim ve Araşııma Hastaneleri eğitim tipi gögüs hastalıkları hastanesi olup ÇiD/YiD-TB, tedavi başarısızlığından gelen ve kronik olguların tedavisi konusunda karar vermede referans hastanelerdir (3).

Tüberküloz teşhisi ve tedavisi; VSD'ler dışında diğer sağlık kurum ve kuruluşlarında yapılmaktadır. Bu durum tüberküloz hastalarına kendisine çok yakın olan bir sağlık kuruluşundan hizmet alabilme ve hekim seçme özgürlüğü gibi avantajlar sağlamaktadır. Ancak değişik sağlık kurum ve kuruluşlarında tüberküloz hastaların kaydı, bildirimi, tanısı ve tedavisi ile ilgili farklı uygulamalar yaşanması gibi dezavantajların oluşmasına neden olabilir. Tüberküloz kontrolünde bu değişik idari yapılar içindeki sağlık birimlerinde hastaların kaydı, bildirimi, tanısı ve tedavisi ile ilgili farklı uygulamalar yaşanmamalıdır.

Çalışmamızda tüberküloz hastalarının \%36.3 ( $\mathrm{n}=$ 310)'üne üniversite hastanelerinde, \%18.5 (n= 158)'ine VSD'de, \%17.3 ( $n=148)^{\prime}$ 'üne devlet hastanelerinde tanı konulduğunu tespit ettik. İzmir Eşrefpaşa VSD'de Ocak 1997-Haziran 1998 döneminde kayıtlı 229 tüberküloz olgunun değerlendiği çalışmada hastaların \%28'inin tanısı dispanserde konulmuştur (4). İzmir Kahramanlar VSD'de 1998 yılında kayıtlı 171 tüberküloz olgunun değerlendirildiği çalışmada hastaların \%22'sine dispanserde tanı konduğu tespit edilmiştir (5). Gaziantep $2 \mathrm{No}$ 'lu VSD'de Ocak 2004-Aralık 2004 tarihleri arasında tüberküloz tanısı alan 51 olgunun değerlendirildiği çalışmada olguların ilk tanı aldıkları kurumlar arasında \%37.2 oranla VSD ilk sırada yer almıştır (6).
Çalışmamızın sonuçlarına göre; akciğer tüberküloz olgularının \%31.3 $(n=157)^{\prime}$ üne VSD'de, \%22.8 ( $n=$ $114)^{\prime}$ ine üniversite hastanelerinde, $\% 16(n=80)^{\prime}$ sına devlet hastanelerinde, \%10.6 ( $n=53)^{\prime}$ sına özel hastanelerde, \%7.4 ( $n=37)^{\prime}$ üne göğüs hastalıkları hastanelerinde, \%6.8 $(n=34)^{\prime}$ ine eğitim ve araştırma hastanelerinde, \%3.5 $(n=18)^{\prime}$ ine referans göğüs hastalıkları eğitim ve araştırma hastanelerinde, \%1.6 ( $n=$ 18)'sına asker hastanelerinde tanı konulmuştur. Malatya VSD'lerinde Ocak 2000-Aralık 2002 tarihleri arasında akciğer tüberkülozu tanısıyla izlenen 470 olgunun incelendiği çalışmada olguların \%44.3 ( $\mathrm{n}=$ $208)^{\prime} \ddot{u}$ VSD'de, \%30.5 ( $\left.n=143\right)$ devlet hastanesi $\left(21^{\prime} \mathrm{i}\right.$ SSK hastanesi), \%11.3 ( $\mathrm{n}=53)$ üniversite hastanesi, \%4.7 ( $n=22)$ göğüs hastanesi, \%3.4 ( $n=16)$ asker hastanesi, \%3 ( $n=14)$ özel hastanede tanı konulmuştur (7).

Akciğer dışı tüberküloz olgularının \%0.3 $(n=1)^{\prime}$ üne VSD'de, \%55.5 ( $n=196)^{\prime}$ ine üniversite hastanelerinde, \%18.7 ( $n=68)^{\prime}$ 'sine devlet hastanelerinde, \%13.3 $(n=47)^{\prime}$ üne özel hastanelerde, $\% 2(n=7)^{\prime}$ sine göğüs hastalıkları hastanelerinde, \%6.8 $(n=34)^{\prime}$ 'ine eğitim ve araştırma hastanelerinde, \%1.4 ( $\mathrm{n}=3)^{\prime}$ 'üne referans göğüs hastalıkları eğitim ve araştırma hastanelerinde, \%1.7 ( $\mathrm{n}=6)^{\prime}$ 'sine asker hastanelerinde tanı konulduğunu tespit ettik. Eskişehir-Deliklitaş VSD'de Ocak 1990-Haziran 2000 tarihleri arasında kayıtlı akciğer dışı tüberkülozlu 239 olgunun değerlendirildiği çalışmada olguların \%28.5 ( $\mathrm{n}=63)^{\prime} \mathrm{i}$ devlet hastaneleri, $\% 25.1(n=57)^{\prime} \mathrm{i}$ üniversite hastaneleri, \%13 ( $\left.\mathrm{n}=29\right)^{\prime}$ ü VSD, \%10.7 $(n=24)^{\prime}$ si asker hastanesi, \%9.4 $(n=21)^{\prime}$ ü SSK hastanesi, \%7.6 $(n=17)^{\prime}$ 'sı göğüs hastanesi, \%3.1 $(n=7)^{\prime}$ i özel hekim, \%2.6 $(n=6)^{\prime}$ sı kurum hastanesinde tanı konulmuştur (8).

Tanı koyulan tüberküloz hastaların \%81.9 ( $\mathrm{n}=$ 699)'una VSD'de, \%7.7 ( $n=46)^{\prime}$ 'sine üniversite hastanelerinde, \%4.3 ( $n=37)^{\prime}$ üne göğüs hastalıkları hastanelerinde tüberküloz tedavisi başlanmıştır. İzmir Eşrefpaşa VSD'de Ocak 1997-Haziran 1998 döneminde kayıtlı 229 tüberküloz olgunun değerlendiği çalışmada tedavi başlama yeri olarak \%74'ünde göğüs hastalıkları eğitim ve araştırma hastanesi, \%7'sinde dispanser olarak tespit edilmiştir (4). İzmir Kahramanlar VSD'de 1998 yılında kayıtlı 171 tüberküloz olgunun değerlendirildiği çalışmada \%78 ( $n=$ $134)^{\prime}$ inin hastanede tedavi başladıktan sonra dispansere başvurduğu tespit edilmiştir (5). 2001 yılında yapılan bölge tüberküloz toplantıları için derlenen 1999 yılı verilerle tüberküloz hastalarının durumunu inceleyen çalışmada hastaların tedavisini başlayan 
kurumlarda değerlendirildiğinde Antalya, Edirne, Denizli, i̇stanbul, Samsun ve Trabzon illerindeki toplam hastaların \%74 ( $n=6.378)^{\prime}$ ünün hastanelerde, \%26 ( $n=2.239)^{\prime}$ sının VSD'lerde tedavisinin başlandığı tespit edilmiştir (9). Van VSD'lerinde Ocak 1999-Aralık 2003 tarihleri arasında takip edilen 645 tüberküloz olgusunun değerlendirildiği çalışmada ise tanı konup tedavi başlama yeri olarak üniversite hastanesinin \%32.9 ile ilk sırayı, \%23.9 ile VSD'lerin ikinci sırayı, \%22.6 ile devlet hastanesinin üçüncü sırayı aldığı tespit edilmiştir (10).

Çalışmamızın sonuçlarına göre; akciğer tüberküloz olgularının \%83.6 $(n=419)^{\prime}$ sına VSD'de, \%4.6 ( $n=$ $23)^{\prime}$ sına üniversite hastanelerinde, $\% 1.2(n=6)^{\prime}$ 'sine devlet hastanelerinde, \%6.6 ( $n=33)^{\prime}$ 'sına göğüs hastalıkları hastanelerinde, \%2 $(n=9)^{\prime}$ 'sine referans göğüs hastalıkları eğitim ve araştırma hastanelerinde tedavileri başlanmıştır. İstanbul'da 18 VSD'de 1995 yılında kayıtlı 2.525 yeni akciğer tüberkülozu olgusunun değerlendirildiği çalışmada olguların \%71 ( $\mathrm{n=}$ $1.791)^{\prime} \mathrm{i}$ hastanede, \%29 $(\mathrm{n}=734)^{\prime} \mathrm{u}$ VSD'de tedavisi başlanmıştır (11). Eskişehir Deliklitaş VSD'de Ocak 1990-Haziran 2000 tarihleri arasında kayıtlı tedavisi tamamlanan 869 akciğer tüberküloz olguların değerlendirildiği çalışmada olguların \%59.4 ( $n=516)^{\prime}$ ü VSD'de, \%15.9 $(n=138)^{\prime}$ u göğüs hastalıkları hastanesinde, \%5.9 $(n=51)^{\prime}$ u üniversite hastanesi, \%4 $(n=$ 35)'ü devlet hastanesi, \%2.9 ( $\mathrm{n}=25)^{\prime} \mathrm{u}$ asker hastanesi, \%2.6 ( $(n=23)^{\prime}$ sı SSK hastanesi, \%1.4 ( $\left.n=12\right)^{\prime}$ ü kurum hastanesi, \%1.7 ( $\mathrm{n}=15)^{\prime}$ 'si özel hekim tarafından tedavisi başlanmışıı (12).

Akciğer dışı tüberküloz olgularının \%79.3 (n= 280)'üne VSD'de, \%12.2 ( $\mathrm{n}=43)^{\prime}$ 'sine üniversite hastanelerinde, \%57 ( $n=20)^{\prime}$ sine devlet hastanelerinde, \%1.1 ( $n=4)^{\prime}$ ine özel hastanelerde ve göğüs hastalıkları hastanelerinde tedavileri başlanmıştır.

\section{SONUÇ}

Çalışmamızda tüberküloz hastalarının hangi sağlık kurumunda tanı konulduğu ve tedaviye başlandığını tespit ettik. Farklı zaman aralığında, farklı illerde, farkIı olgu tanımları ile yapılan dispanser çalışmalarında VSD'lerde tanı koyma oranı \%13-44.3 arasında; tedavi başlama \%7-59.4 arasında değişmektedir. Çalışmamızda hastalarının \%18.5'ine VSD'de, tanı konulmuştur; tanı koyulan bu hastaların \%81.9'una VSD'de tüberküloz tedavisi başlanmıştır. Çalışmamızda tedavi başlamada yüksek oranla VSD'nin ilk sırada olması VSD'lerin tüberküloz kontrol programındaki önemini ve diğer merkezlerin de bu konudaki farkındalıklarının yeterli düzeyde olduğunu göstermektedir.

\section{ÇIKAR ÇATIŞMASI}

Bildirilmemiştir.

\section{KAYNAKLAR}

1. Özkara Ş. Türkiye'de Verem Savaşı. In Ed. Özkara Ş, Kılıçaslan Z. Tüberküloz. Türk Torkas Derneği Toraks Kitapları, 2010, istanbul: 661-72.

2. Musaonbaşıŏ̆lu S, Yıldırım A, Mutlu SM, Baykal F. Türkiye'de Verem Savaşı 2012 Raporu, Ankara: Türkiye Halk Sağlığı Kurumu, 2013.

3. Tüberküloz Tanı ve Tedavi Rehberi, Ankara: Türkiye Cumhuriyeti Sağlık Bakanlığı, 2011.

4. Kıter G, Coşkunol i, Alptekin S. İzmir Eşrefpaşa Verem Savaş Dispanser'inde Ocak-1997-Haziran 1998 döneminde kayıtlı tüberkülozlu hastaların değerlendirilmesi. Tuberk Toraks 2000;48:333-9.

5. Öztop A, Ünsal i, Çiftci E, Çakmak R. İzmir Kahramanlar VSD'de 1998 yılında kayıtlı tüberküloz hastalarının değerlendirilmesi. Solunum Hastalıkları, 2003;14:117-24.

6. Elbek O, Yardı AD, Uyar M, Tanrı̈ver M, Börekçi Ş, Dikensoy Ö. Gaziantep 2 No'lu Verem Savaş Dispanseri'nin 2004 yılı izlem sonuçları. Tuberk Toraks, 2006; 54:341-8.

7. Hacıevliyagil SS, Duran M, Mutlu LC, Günen H, Şenoğlu A, Evliyaoğlu E, et al. Malatya Verem Savaş Dispanserlerinde izlenen akciğer tüberkülozlu hastaların değerlendirilmesi. Solunum Hastalıkları, 2006; 17:177-85.

8. Kolsuz M, Ersoy S, Demircan N, Metintaş M, Erginel S, Uçgun i. Eskişehir-Deliklitaş Verem Savaş Dispanseri'nde izlenen akciğer dışı tüberküloz olgularının değerlendirilmesi. Toraks Dergisi 2003;4:25-32.

9. Özkara Ş, Kılıçaslan Z, Öztürk F, Seymenoğlu S, Erdoğan AR, Tellioğlu C, et al. Bölge verileriyle Türkiye'de tüberküloz. Toraks Dergisi 2002;3:178-87.

10. Özbay B, Sezgi C, Altınöz O, Sertoğullarından B, Tokgöz N. ilimizde 1999-2003 yılları arasında saptanan tüberküloz olgularının değerlendirilmesi. Tuberk Toraks 2008;56:396404.

11. Karagöz T, Arda H, Erboran T, Kılıçaslan Z, Çağlar E, Erem $A R$. Istanbul dispanserleri çalışmalarının yeni akciğer tüberkülozlu olguların tanı-tedavi ve takip işlemleri açısından değerlendirilmesi. Tuberk Toraks 2000;48:128-35.

12. Kolsuz M, Ersoy M, Küçükkebapçı C, Metintaş M, Uçgun $i$, Erginel S. Eskişehir Deliklitaş Verem Savaş Dispanseri'nde kayıtı akciğer tüberkülozu olgularının değerlendirilmesi. Tuberk Toraks 2003;51:163-70. 
Copyright of Tuberculosis \& Thorax / Tuberkoloz ve Toraks is the property of Turkish Association of Tuberculosis \& Thorax and its content may not be copied or emailed to multiple sites or posted to a listserv without the copyright holder's express written permission. However, users may print, download, or email articles for individual use. 